\title{
PRÁTICAS DISCURSIVAS RELIGIOSAS NA ESFERA PÚBLICA: EXAME DE UM "MANUAL DE BIOÉTICA" E SEUS ENUNCIADOS SOBRE A “TEORIA DE GÊNERO" ATRAVÉS DO PENSAMENTO DE HABERMAS
}

Heiberle Hirsgberg Horácio*

Para Cris e Elis

\section{RESUMO}

Este artigo pretende apresentar apontamentos e questionamentos que possam permitir reflexões sobre os modos de operar da religião na esfera pública. Para tanto, examinará as possíveis estratégias enunciativas e práticas discursivas mobilizadas por um produto informativo utilizado por um segmento religioso para ser executado na esfera pública. Designadamente, este artigo utilizará como elemento fomentador os debates em torno da "distribuição" de um "Manual de Bioética" católico no X Fórum de Ensino Religioso do Estado do Rio de Janeiro, bem como o exame dos enunciados relacionados à "Teoria de Gênero" presentes nesse "Manual". Os exames de ambas as práticas, a da distribuição e a prática discursiva, serão feitos sob a perspectiva habermasiana.

Palavras-chave: religião; teoria de gênero; esfera pública

* Doutor e mestre PPCIR-UFJF, especialista em Planejamento, Implementação e Gestão em EAD (UFF), em TV, Cinema e Mídias Digitais (UFJF), em Filosofia (UFOP) e graduado em Filosofia (UFSJ). Professor efetivo do Departamento de Filosofia e Coordenador do curso de Ciências da Religião da Universidade Estadual de Montes Claros. 
RELIGIOUS DISCURSIVE PRACTICES IN THE PUBLIC SPHERE:

EXAMINED IN THE LIGHT OF THE THOUGHT OF HABERMAS, AND ILLUSTRATED BY THE CASE OF A "MANUAL OF BIOETHICAL" AND THEIR STATEMENTS ABOUT "GENDER THEORY"

\begin{abstract}
This article aims to present notes and questions that will allow reflections on the ways to operate of religion in public sphere. Thus, will examine possible declared strategies and discursive practices mobilized by an informational product built by a religious segment to be executed in the public sphere. It means, this article will use as a developer element the debates around the "distribution" of a "Manual of Bioethical" Catholic in the X Fórum de Ensino Religioso do Estado do Rio de Janeiro, as well as the examination of the statements related to "Gender Theory " present in this "Manual" . The reviews of both practices, the distribution and discursive practice, will be made under the Habermas' perspective.
\end{abstract}

Keywords: religion, gender theory; public sphere

\title{
PRÁTICAS DISCURSIVAS RELIGIOSAS EN LA ESFERA PÚBLICA: EXAMEN DE UN "MANUAL DE BIOÉTICA" Y SUS ENUNCIADOS SOBRE “TEORIA DE GÉNERO” BAJO LA LUZ DEL PENSAMIENTO DE HABERMAS
}

\begin{abstract}
RESUMEN
Este artículo pretende presentar apuntamientos y cuestiones que puedan permitir la reflexión sobre las formas de operar de la religión en el espacio público. Para ello, examinará posibles estrategias enunciativas y prácticas movilizadas por un producto informativo construido por un segmento religioso para ser ejecutado em la esfera pública. Designadamente, este artículo utilizará como elemento desarrollador de debates en torno de la "distribución" de un "Manual de Bioética" católico en el X Foro de Enseñanza Religiosa del Estado de Rio de Janeiro, bien como el exámen de los enunciados referidos a la "Teoría de Género" presentada en ese "Manual". Los exámenes de ambas las prácticas, aquella de la distribución y la práctica discursiva, serán hechos bajo la perspectiva habermasiana.
\end{abstract}

Palavras-clave: religión; teoria de género, esfera pública 


\section{INTRODUÇÃO}

Muitos são os trabalhos que versam sobre religião e espaço público no Brasil. Para mencionar só alguns livros publicados com essa temática específica, pode-se elencar o livro Religião e Espaço Público organizado em 2003 pela pesquisadora Patrícia Birman, o livro A religião no espaço público organizado em 2012 pelos autores Pedro Oro, Steil, Cipriani e Giumbelli, o livro Religião e espaço público: cenários contemporâneos organizado por Áurea Marin Burocchi e Jaldemir Vitório, bem como, a recente publicação organizada por Emerson Sena da Silveira e Manoel Ribeiro com o título Religião, política e espaço público no Brasil (2015).

Obviamente, os trabalhos que pensam a religião e o espaço público o fazem através de perspectivas diversas. Existem, desde aqueles trabalhos que se interessam por observar as articulações religiosas em uma sociedade classificada por eles de "pós-secular", até aqueles que observam como o Estado brasileiro "foi legitimando à presença do religioso no espaço público", como o estimulante trabalho do antropólogo Emerson Giumbelli (2008)'. Ademais, existem, ainda, aqueles trabalhos que se propõe a "repensar o problema das relações entre a esfera religiosa e a esfera pública do ponto de vista das práticas discursivas dos atores, enfatizando o modo como interagem em controvérsias específicas" (Paula MONTERO, 2012).

Este artigo pretende apresentar apontamentos e questionamentos que possam permitir reflexões sobre os modos de operar da religião na esfera pública. Para tanto, examinará as possíveis estratégias enunciativas e práticas discursivas mobilizadas por um produto

\footnotetext{
No trabalho mencionado, "toma-se como problema central especificar as formas pelas quais se configuram relações de reconhecimento do religioso pelo Estado no Brasil no quadro definido pelo regime republicano. Em outras palavras, considerando a laicidade - por causa dela ou apesar dela -, como o Estado foi legitimando a presença do religioso no espaço público. No caso da Igreja Católica, isso ocorreu inicialmente por meio de uma aliança simbólica e material e com a ajuda de um regime jurídico de baixo controle estatal. No caso do espiritismo, ocorreu em meio a uma batalha pela legitimidade de práticas com algum sentido terapêutico. No caso dos cultos afros, envolveu a aceitação de um argumento culturalista. Partindo do delineamento histórico de diferentes modalidades de reconhecimento, busca-se a caracterização do que ocorre atualmente, considerando a presença dos evangélicos no espaço público. De modo geral, trata-se de problematizar a definição de fronteiras no interior do campo religioso e nas relações entre religião, sociedade e Estado no Brasil." (Emerson GIUMBELLI, 2008)
} 
informativo utilizado por um segmento religioso para ser executado na esfera pública. Designadamente, este artigo utilizará como elemento fomentador os debates em torno da "distribuição" de um "Manual de Bioética" católico no X Fórum de Ensino Religioso do Estado do Rio de Janeiro, bem como o exame dos enunciados relacionados à "Teoria de Gênero" presentes nesse "Manual". Os exames de ambas as práticas, a da distribuição e a prática discursiva, serão feitos sob a perspectiva habermasiana.

Vale destacar que embora nos enunciados supramencionados do "Manual" existam significativas questões relacionadas à Teoria de Gênero que poderiam ser imprescindivelmente discutidas sob a luz das perspectivas das estudiosas e estudiosos dessa (s) teoria (s), esses enunciados serão examinados a partir das reflexões da "esfera pública" de Jürgen Habermas, mesmo que reconheçamos, assim como fez o próprio Habermas, as críticas relacionadas às questões de gênero que este modelo sofre ${ }^{3}$ (Nancy FRASER, 2003; 1992). No entanto, consideramos que o ponto de vista habermasiano é ainda capaz de oferecer bom rendimento para os debates relacionados à "conciliação" de discursos plurais na esfera pública ${ }^{4}$.

2 A denominação Manual de Bioética para se referir ao livreto "Keys to Bioethics" (Chaves para a Bioética) foi utilizada originalmente pelos pesquisadores, mobilizados neste artigo, Medeiros e Monsores. Por esse motivo os termos aparecem entre aspas neste texto.

3 Nessa específica ordem de críticas, existem aquelas que condenam a concepção habermasiana por ela não compreender a esfera pública como um espaço de disputas, de relações de força e de poder, relações que implicariam em dominações e opressões. Por isso, tal concepção restringiria a esfera pública e não consideraria os excluídos, como as mulheres. No entanto, concordamos com o pesquisador Fernando Perlato que considera que Habermas reconhece as críticas e que por isso "acabou por ampliar posteriormente seu conceito de esfera pública (...)" (Fernando PERLATO, 2012.

4 Várias são as críticas, e também as reformulações, à concepção habermasiana. Todavia, embora concordemos com muitas dessas críticas, também observamos que a concepção é no mínimo importante para certos tipos de reflexões. Importância que pode ser constatada quando "a obra de Habermas tem exercido enorme influência na reflexão sobre os dilemas e desafios da democracia brasileira". Para ver a relação das críticas sofridas pela concepção habermasiana, reformulações e potencialidades para o caso do Brasil: Fernando PERLATO, 2012. 


\section{CONTEXTUALIZAÇÃO DA ENTREGA DO “MANUAL": UM EVENTO VINCULADO AO ENSINO RELIGIOSO CONFESSIONAL DO RIO DE JANEIRO}

Nesta parte do texto observar-se-á os motivos da distribuição do “Manual” em um evento do Estado do Rio de Janeiro para os professores de Ensino Religioso, bem como a relação dessa distribuição com o currículo mínimo de Ensino Religioso confessional do supramencionado Estado. Para tanto, antes, exibir-se-á a estruturação do Ensino Religioso confessional do Rio de Janeiro.

Em 14 de setembro de 2000, o então governador do Estado do Rio de Janeiro, Anthony Garotinho, sancionou a lei 3459. Segundo esta lei, o Ensino Religioso deveria ser disponibilizado "na forma confessional" de acordo com as preferências manifestadas pelos próprios alunos a partir de 16 anos, inclusive, assegurado o respeito à diversidade cultural e religiosa do Estado do Rio de Janeiro, vedadas quaisquer formas de proselitismo" (LEI 3459/00).

Na lei está inserida também que o "conteúdo do ensino religioso é atribuição específica das diversas autoridades religiosas, cabendo ao Estado o dever de apoiá-lo integralmente" (LEI 3459/00).

Baseadas nas orientações acima, as instituições educacionais públicas estaduais deveriam, para as aulas de Ensino Religioso, separar os alunos por salas de acordo com a religião de cada um. Para que a lei fosse integralmente cumprida, o colégio precisaria possuir tantos professores (católicos, evangélicos, judeus, etc.) quantas eram às salas das religiões existentes na escola e a demanda dos alunos. Vale destacar que no ato do concurso de admissão da SEEDUC-RJ, o professor indicava seu credo, uma vez que, ele deveria fazer o concurso para ministrar apenas aulas da sua religião.

Isso significa um Ensino Religioso que é atribuição específica das autoridades religiosas, com o objetivo de ensinar os conteúdos e dogmas exclusivos da religião escolhida pela (o) aluna (o). Este trabalho que questiona um Ensino Religioso confessional, possui afinidades com o modelo, indicado por Décio Passos, das Ciências da Religião, que possui pressupostos educacionais e reconhece "a religiosidade e a religião como dados antropológicos e socioculturais que devem ser abordados no conjunto das demais disciplinas escolares por razões cognitivas e pedagógicas" (João Décio PASSOS, 2007, p. 32). 
Em outro trabalho explanamos como a separação por confessionalidade deu origem a impasses significativos. Dessa orientação surgiram expressivos problemas oriundos da realização de uma disciplina confessional em um ambiente de religiosidades diversas. Até mesmo pela falta de estrutura ${ }^{6}$ e professores que pudessem dar conta da diversidade religiosa dos alunos7 ${ }^{7}$ (Heiberle HORÁCIO, 2015).

Conquanto seja imprescindível a discussão sobre os impasses supracitados, nós o arrolamos para demonstrar que eles compuseram um conjunto de questões e dificuldades que levaram à criação de um Currículo Mínimo de Ensino Religioso.

Sendo assim, observamos que o Currículo Mínimo de Ensino Religioso do Estado do Rio de Janeiro foi uma tentativa de construção de um instrumento de ajustes, aprimoramento e reparação, dos impasses supramencionados resultantes da implantação da Lei 3459/00, e de uma organização de Ensino Religioso confessional.

Concluído para ser utilizado no ano de 2014, o Currículo Mínimo de Ensino Religioso teve sua “concepção, redação, revisão e consolidação conduzidas por uma equipe de professores da rede estadual. Professores de todos os credos credenciados com representantes na rede" (Currículo mínimo, RIO DE JANEIRO, 2013, p.2).

O Currículo Mínimo, que possuía uma separação por ciclos, tinha orientações para 4 ciclos, sendo que o primeiro ciclo englobava os $6^{\circ} \mathrm{e}$ $7^{\circ}$ anos, o segundo ciclo $8^{\circ}$ e $9^{\circ}$ anos, o terceiro ciclo $1^{\text {a }}$ e $2^{\text {a }}$ séries do Ensino Médio, e o quarto ciclo $2^{\mathrm{a}}$ e $3^{\mathrm{a}}$ séries do Ensino Médio.

O terceiro ciclo, que tinha como eixo o "Diálogo: Fé, ciência e cultura", possuía como orientação para o terceiro bimestre desse eixo o mote Fé e Ciência. Neste constavam as seguintes habilidades e competências: "analisar as teorias científicas sobre a Origem e, articular as

6 De acordo com a lei, conquanto seja obrigatório o oferecimento da disciplina pelo colégio, a matrícula do aluno é facultativa. Essa orientação prevê que os colégios tenham atividades alternativas para aqueles alunos que optarem por não assistir às aulas de Ensino Religioso, ou que não tenham professores das suas religiões. Nesse caso, o problema se dá porque os colégios nem sempre possuem uma estrutura onde possam providenciar atividades alternativas.

7 Trabalhos destacam a exclusão e os abusos sofridos pelas religiões de matriz-africana nesse tipo de organização de Ensino Religioso, já que a maioria dos professores é católica ou evangélica (Stela CAPUTO, 2012, 218). 
relações entre a fé e as demais ciências, suas implicações, impactos e repercussões". No $4^{\circ}$ Bimestre com o tema Fé e Questões contemporâneas, as habilidades e competências são: "ler os fatos do mundo contemporâneo à luz da fé e analisar os impactos das novas tecnologias na concepção antropológica diante da transcendência." (Currículo mínimo, RIO DE JANEIRO, 2013).

No quarto ciclo se encontravam as orientações do $3^{\circ}$ Bimestre o tema: Questões atuais da Bioética e Biodireito. Neste tema temos as seguintes competências e habilidades: "refletir sobre questões atuais da Bioética e Biodireito tais como: eutanásia; clonagem; pena de morte; fecundação in vitro; pesquisas com células-tronco; etc." (Currículo mínimo, RIO DE JANEIRO, 2013).

Conforme também já demonstrado por nós em outro trabalho, várias foram as dificuldades para a aplicação adequada do Currículo Mínimo de Ensino Religioso, bem como muitas foram as falas de professores que mencionavam dúvidas e problemas para desenvolverem o Currículo Mínimo (Heiberle HORÁCIO, 2015). Dúvidas e dificuldades constatadas por nós em nossas participações em fóruns ${ }^{8}$ de discussões sobre o Ensino Religioso, em nossa atuação profissional ${ }^{9}$, e em entrevistas por nós realizadas com os professores.

Esses professores acima mencionados, em suas falas sempre evidenciaram a necessidade de um instrumento que os auxiliassem no trabalho com o Currículo Mínimo. Supomos, nós e alguns professores entrevistados por nós, que daí tenha surgido a ideia da "distribuição" do "Manual de Bioética". Já que conversando com os professores de Ensino Religioso observamos que vários deles aprovaram a entrega do "Manual de Bioética", no X Fórum de Ensino Religioso do Estado do Rio de Janeiro, alegando que necessitavam de um instrumento de orientação. Para os pesquisadores que serão utilizados como vozes no

8 Ministrei palestras, comunicações e minicursos nos seguintes eventos: Terceira Semana de Ciência da Religião da UFJF (2013), IV Seminário Regional da diversidade educacional: direitos e mudanças sociais na escola (2014), Terceira Jornada de Ciências Sociais da UFJF (2014), XVII Jornadas sobre Alternativas Religiosas na América Latina-2013 e XIV Simpósio Nacional da ABHR (2015).

9 Fui professor do Estado do Rio de Janeiro durante 10 anos e, conquanto eu tenha sido professor das disciplinas Filosofia e Sociologia, procurei acompanhar o funcionamento da disciplina de Ensino Religioso em dois colégios estaduais do Rio de Janeiro. 
debate sobre o Manual, Medeiros e Monsores (2014, p.6), "inicialmente, parece claro que o Manual de Bioética da Igreja Católica entra, direta ou indiretamente (por meio do discurso), na escola e nas aulas de Ensino Religioso através, principalmente, dos professores do credo católico".

No entanto, indiferente do motivo da entrega do material, ele gerou debates entre professores e pesquisadores no ano de 2014 e no ano de 2015, e ainda que haja atualmente uma orientação para a não realização de aulas relacionadas aos temas vinculados à Bioética e Biodireito, os debates gerados em torno desses temas, e que explanaremos a seguir, são utilizados por nós como elementos fomentadores para as nossas reflexões sobre as possíveis estratégias enunciativas mobilizadas por um produto informativo construído por um segmento religioso para ser executado na esfera pública.

\section{O MANUAL DE BIOÉTICA, DE UM POSSÍVEL MATERIAL AUXILIADOR} A OBJETO DE DEBATE, INCLUSIVE SOBRE A “TEORIA DE GÊNERO"

$O$ debate que supramencionamos ocorreu em torno da "distribuição" de um "Manual de Bioética" católico no X Fórum de Ensino Religioso do Estado do Rio de Janeiro. Evento ocorrido no dia 27 de março de 2014 no auditório da Secretaria de Estado de Educação-RJ.

O Fórum, que teve como tema Fraternidade um grito por dignidade, de acordo com os pesquisadores Cristiano S. de Medeiros e Luciana Helena Monsores (2014), procurou destacar, através de seus enunciados explícitos, a importância do respeito aos diversos credos e crenças no Ensino Religioso do Estado do Rio de Janeiro. Todavia, para os pesquisadores acima mencionados, esses enunciados destacados talvez não tenham sido integralmente respeitados, uma vez que conforme os pesquisadores:

Daí, observamos que mesmo "respeitando" todas as crenças, como assim queriam passar nas suas mensagens iniciais, o tema do Fórum se resumiu ao tema da Campanha da Fraternidade de 2014, da Igreja Católica - "Fraternidade um grito por dignidade." (Cristiano MEDEIROS; Luciana MONSORES, 2014, p.2)

Vale destacar que o fato de os Fóruns de Ensino Religioso do Estado do Rio de Janeiro terem sempre os mesmos temas das Campanhas 
da Fraternidade, é apenas um dos vários questionamentos que alguns pesquisadores fazem sobre o Ensino Religioso do Estado do Rio de Janeiro. Ademais, existem críticas referentes ao proselitismo velado em torno das religiões católica e evangélicas, em contraposição às religiões de matriz africana (Stela CAPUTO, 2012).

Em que pese a importância dos questionamentos supramencionados, gostaríamos aqui de chamar a atenção para o debate ocorrido em torno da distribuição dos exemplares do Keys to Bioethics (Chaves para a Bioética), no X Fórum de Ensino Religioso.

Segundo os pesquisadores, Cristiano Medeiros e Luciana Monsores que assistiram ao evento, todos os que compareceram ao Fórum de Ensino Religioso receberam uma "bolsa-kit" que continha um bloco de notas, um cartão postal do Centro Cultural da Bíblia, um folder com a programação do evento, a declaração de comparecimento, um certificado, uma revista da Sociedade Bíblica do Brasil, um caderno da Campanha da Fraternidade 2014, o Currículo Mínimo de Ensino Religioso e um exemplar do Keys to Bioethics (Chaves para a Bioética), por eles denominado: "Manual de Bioética" católico, entregue na Jornada Mundial da Juventude, ocorrida no Brasil, em 2013 (IBIDEM, p. 3). Vale destacar que, alguns professores de Ensino Religioso mencionam que o Manual não foi entregue a todos os participantes, e que seu recebimento era opcional.

De todo modo, o supracitado "Manual" fomentou críticas e debates que vieram a se juntar aquelas críticas supramencionadas. Para alguns pesquisadores, o "Manual" traz uma visão unilateral de diversos temas, chegando a ser homofóbico e machista (Cristiano MEDEIROS; Luciana MONSORES, 2014).

Os pesquisadores Medeiros e Monsores criticam que o "Manual", que apresenta posicionamentos acerca do estupro, aborto, da utilização de métodos contraceptivos, homossexualidade, entre outros, coloca como se ele "tratasse de uma apresentação objetiva das grandes questões de bioética com as quais somos todos confrontados, o que nos deixa frequentemente desamparados" (CHAVES PARA A BIOÉTICA, 2013), conforme se pode observar pela citação.

Para Medeiros e Monsores, "o manual torna claras as posições que os cristãos devem tomar: ser contra a homossexualidade, ser contra o 
aborto, mesmo em casos de estupro, ser contra famílias não tradicionais, a eutanásia, a inseminação artificial e pesquisas com células-tronco embrionárias" (Cristiano MEDEIROS; Luciana MONSORES, 2014, p.6). Para os pesquisadores, o "Manual” não leva em conta a Teoria de Gênero, ou melhor, segundo eles leva em conta de maneira depreciativa. Ademais, de acordo com Medeiros e Monsores, "o discurso sobre a questão do gênero e da orientação sexual proferido pela Igreja no manual de bioética afirma que a homossexualidade é uma doença que pode ser tratada e é ignorada por pesquisadores e ativistas que defendem a teoria do gênero" (IBIDEM).

Cristiano Medeiros e Luciana Monsores afirmam ainda que "o texto condena, além da homossexualidade", a transexualidade e a adoção de crianças por casais do mesmo sexo, com afirmações do tipo: "há realmente apenas uma maneira para criar uma criança: a união de um homem e uma mulher; e "não de duas pessoas do mesmo sexo que formam um casal $^{10}$ (...)”. (CHAVES PARA A BIOÉTICA, 2013). Podemos observar ainda trechos como o que segue, contrário à adoção de crianças por casais do mesmo sexo:

Naturalmente, é essencial ser amado pelos pais, mas não basta. Criar um filho ultrapassa o lado afetivo, embora todos os componentes se misturem. Sabemos muito bem que pai e mãe não são intercambiáveis. Cada qual contribui para o filho de modo diferente, permitindo que este construa a própria identidade, notadamente sexual. Sejamos realistas: nascemos menino ou menina. A procriação precisa de pai e mãe. A criança precisa de pai e mãe para se desenvolver. Observamos que em casos de dificuldade os psicólogos apelam para pai e mãe para solucionar o problema relacional do filho. As respostas do pai e da mãe enriquecem umas às outras, complementam-se e permitem resolver problemas. (CHAVES PARA A BIOÉTICA, 2013).

Além das afirmações como as mencionadas acima, na parte reservada, a Teoria de Gênero, o "Manual”, traz charges, como as que apresentamos abaixo, que ilustram de um modo esclarecedor a perspectiva assumida pelo "Manual” e o que nele é criticado pelos pesquisadores.

10 O "Manual" afirma que duas pessoas do mesmo sexo não formam um casal por não poderem gerar um filho (CHAVES PARA A BIOÉTICA, 2013, p.72). 
1 - Chaves para Bioética, 2013.

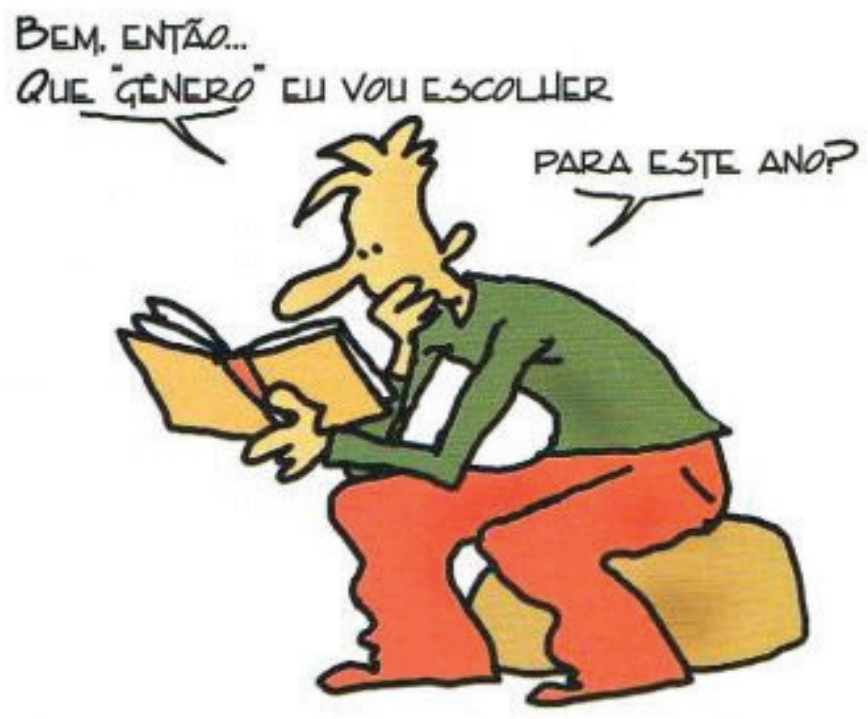

2 - Chaves para a Bioética, 2013.

ENTRE OS CANGURUS. SERA QUE É A SOCIEDADE QULE DECIDE..

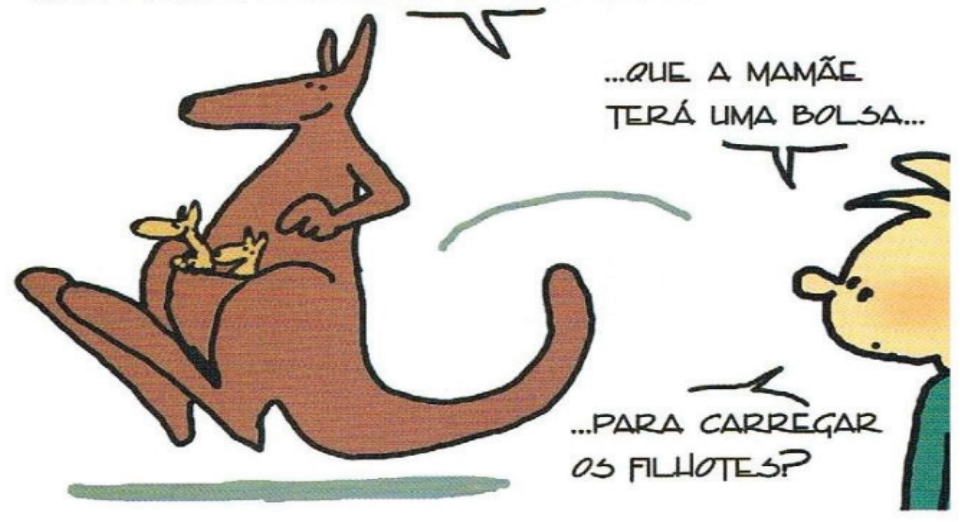


3- Chaves para Bioética, 2013.

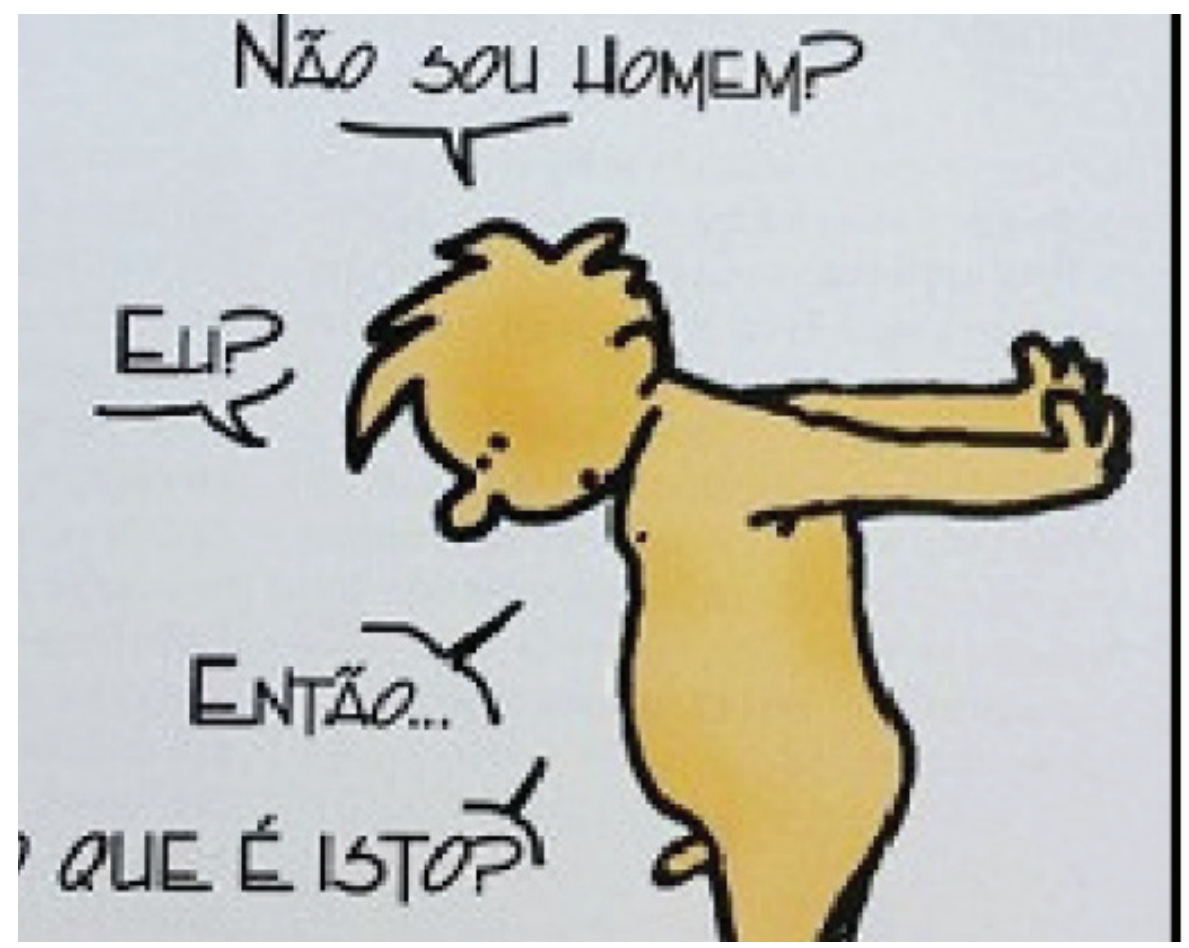

Antes de tecermos reflexões sobre a possibilidade de o "Manual" servir como instrumento orientador de processos educacionais, bem como sobre as concepções nele expostas, como vimos nas charges e nos trechos exibidos acima, ponderaremos sobre o fato de ele ter sido distribuído em um evento estatal, i.e., de ter sido distribuído em um kit no Fórum organizado pela Secretaria de Educação do Estado do Rio de Janeiro, que possui um Ensino Religioso confessional.

Destarte, nossa reflexão imediata está relacionada à tentativa de alocação de uma perspectiva religiosa em uma instituição pública, através, por exemplo, da distribuição de um "Manual” católico em um evento oficialmente estatal, e de um Ensino Religioso confessional. "Manual" que de alguma forma pode ter sido distribuído para o auxílio da prática do Ensino Religioso em um colégio público que deveria possuir um Ensino Religioso não confessional. 
Destacamos que alguns tipos de ações de inserção do religioso são questionados, inclusive sob a óptica de grandes estudiosos que reconhecem a legitimidade da participação religiosa na esfera pública. Referimo-nos à perspectiva, por exemplo, do filósofo Jürgen Habermas ${ }^{11}$.

Para o filósofo alemão Jürgen Habermas, proponente de um modelo procedimental-deliberativo ${ }^{12}$ de democracia, a legitimidade da religião na esfera pública é oriunda da ideia de que em uma sociedade democrática os indivíduos devem ter as suas aspirações de não crenças, crenças e identidades respeitadas. Para ele, a religião é mais uma agência atuante, entre outras, e "o Estado liberal não deve impor aos seus cidadãos religiosos obrigações assimétricas" (Jürgen HABERMAS, 2007).

Segundo o filósofo, a importância da religião na esfera pública se dá inclusive porque ela "constitui uma reserva de valores éticos e culturais que podem eventualmente reforçar a consciência das normas e a solidariedade dos cidadãos em um contexto de crise da razão secular" (Philippe PORTIER, 2013, p.59). Além disso, as religiões podem colaborar na construção de "formas sensíveis de uma convivência humana" e,

os próprios cidadãos seculares como também os crentes de outras denominações podem, sob certas condições, aprender algo das contribuições religiosas, tal como acontece, por exemplo, quando eles

1 Perspectiva criticada por autores como C. Taylor. Segundo o pesquisador Fernando Perlatto, Taylor critica Habermas, e também o filósofo político liberal J. Rawls porque para Taylor "esses autores, ao refletirem sobre a necessidade de um Estado laico, concentram suas preocupações somente na religião como se ela fosse um 'caso especial' que colocasse questões morais radicalmente diferentes de outras tradições intelectuais no contexto da modernidade. Ancorados naquilo que chama de 'Mito do Esclarecimento', esses autores não apenas confeririam um status superior à 'razão autossuficiente' frente à razão religiosa, mas, de forma equivocada, não perceberiam o quanto esta também se constrói a partir de crenças e valores. Para Taylor, se há necessidade de um filtro institucional de forma a 'traduzir' para as instituições políticas formais os discursos religiosos que circulam na esfera pública, como deseja Habermas, este não deveria valer apenas para esses, como se somente as formulações religiosas fossem portadoras de visões morais e valorativas do mundo." (Fernando PERLATTO, 2013, p.145)

12 Modelo que também sofre críticas, como, por exemplo, a de Chantal Mouffe, que observa que o deliberacionismo habermasiano é insatisfatório para responder democraticamente aos desafios do pluralismo. De acordo com Melo, para Mouffe, "o preço político a se pagar pela ênfase no consenso é o da exclusão de pontos de vista a ele irreconciliáveis, e isto, em última instância, não poderia alavancar processos democráticos" (Rodrigo MELLO, 2015, p.137).

Mandrágora, v.22. n. 2, 2016, p. 125-147 
conseguem reconhecer, nos conteúdos normativos de uma determinada exteriorização religiosas, certas intuições que eles mesmos compartilham, as quais, porém, foram olvidadas, às vezes, há muito tempo (Jürgen HABERMAS, 2007, p.148).

No entanto, vale destacar que o mesmo Habermas é defensor incontestável da separação institucional entre Estado e Igreja, mesmo reconhecendo a importância da religião na esfera pública, já que ele é a favor da aceitação do pluralismo de opiniões e crenças. De acordo com Habermas, o respeito ao pluralismo, à convivência tolerante e à igualdade de direitos, só se dá quando o Estado de direito é "neutro do ponto de vista das imagens do mundo" (IBIDEM, p.9). Além disso, a separação institucional entre Estado e religião é considerada por ele uma das "grandes contribuições da democracia institucional" (Philippe PORTIER, 2013, p.72). Sendo assim, segundo o pesquisador francês Philippe Portier, Habermas se

situa no terreno clássico dos direitos civis. Cada cidadão, explica ele, deve ser respeitado em suas opiniões pessoais. Este é o código da democracia liberal: neutro em relação às diferentes visões de mundo - razão pela qual é preciso defender a ideia de separação institucional entre Estado e as Igrejas - o poder político, em seu seio, está destinado a aceitar o pluralismo de opiniões e das crenças (Philippe PORTIER, 2013, p. 66).

Consideramos que as contribuições de Habermas podem amparar o nosso posicionamento, que observa como perigosa a inserção de um material religioso e a distribuição do "Manual católico" em um evento estatal, como também um Ensino Religioso confessional. Sopesamos que tal ação corre o risco de não respeitar uma separação tão fundamental, não levando em consideração a distinção entre participação da religião na esfera pública e a alocação da religião nas instituições pública-estatais, sendo que esse pode ser o caso da inserção do "Manual”. Ou seja, em termos habermasianos, é necessário que não confundamos a utilização de argumentos religiosos por cidadãos religiosos na "esfera da formação da opinião (o espaço político público)" com o uso de argumentos religiosos na "esfera da decisão política (o espaço governamental)" (IBIDEM, p.73). Além disso, 
na democracia, nem o governo, nem a administração, nem a autoridade judiciária podem fazer uso de uma argumentação religiosa para fundamentar os seus atos; primeiramente porque seria faltar à ideia da 'neutralidade do Estado em relação às visões de mundo', depois porque 'as leis devem ser justificadas em uma língua que todos os cidadãos compreendam' (Jürgen HABERMAS, 2007).

Vale destacar que, mesmo que alguns professores defensores da distribuição do "Manual” aleguem que o "Manual Católico" deva ser distribuído aos professores católicos, em um evento estatal, porque é o Estado quem estabeleceu através da lei 3459, o Ensino Religioso confessional no Rio de Janeiro, outro ponto importante que deve ser levado em conta nessa situação, está relacionado ao fato de o "Manual" possuir argumentos e uma estrutura discursiva que atente contra o respeito à diversidade cultural. Diversidade que também está assegurada na mesma lei mobilizada pelos professores. É necessário se levar em conta que os alunos podem pertencer a famílias homoparentais ou monoparentais, e que as afirmações feitas pelo "Manual" podem desrespeitar a diversidade cultural dos alunos, uma vez que elas são orientadas por uma perspectiva que afirma que: "a "confusão de papéis sexuais mina a família e leva a alegações de que outras formas de família têm igual dignidade" (CHAVES PARA A BIOÉTICA, 2013).

Vale destacar que para os pesquisadores Medeiros e Monsores o “Manual de Bioética aborda o 'novo modelo de família' e uma 'nova organização social' como as consequências negativas da teoria de gênero para a sociedade" (Cristiano MEDEIROS; Luciana MONSORES, 2014, p.11).

Aqui mais uma vez mobilizamos Habermas que diz que a participação da religião na esfera pública só é possível se essas fizerem o “aprendizado dos princípios democráticos" (Philippe PORTIER, 2013, p.74). Além disso, de acordo com Habermas, é necessário, para a operacionalização do discurso religioso nas instituições públicas, um processo de tradução dos conteúdos religiosos para uma "linguagem universalmente acessível”, que se necessário deve passar por um "filtro institucional". Ou seja:

Os religiosos deveriam ser livres para expressarem suas opiniões e valores na esfera pública, mas a apropriação das tradições religiosas 


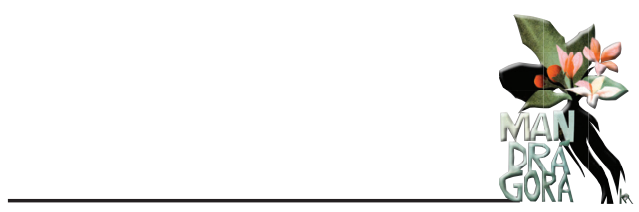

pela cultura política e pelas instituições democráticas contemporâneas só poderia se dar após um processo prévio da tradução de seus conteúdos para um idioma secular e para uma linguagem universalmente acessível.

Um filtro institucional, estabelecido entre o fluxo comunicativo da esfera pública e as deliberações formais nos corpos políticos, deveria ser capaz de traduzir os discursos religiosos antes de seu ingresso na agenda parlamentar, nas cortes e nos corpos administrativos (Jürgen HABERMAS, APUD Fernando PERLATTO, 2011, p. 143).

Consideramos também que a necessária tradução supramencionada poderia trazer os seguintes benefícios:

Por um lado, ela não colocaria quaisquer restrições ao discurso religioso no debate público - um problema do qual padeceria a formulação rawlsiana ${ }^{13}$-, possibilitando tanto a inclusão dos insights valiosos trazidos pela religião, quanto a dinamização e vitalização da esfera pública mediante a participação polifônica de vozes provenientes de diferentes segmentos da sociedade. [...]

Por outro lado, o estabelecimento de um filtro institucional entre os debates na esfera pública e a deliberação nos corpos políticos formais asseguraria tanto a manutenção rigorosa de uma concepção secular do Estado, quanto o objetivo liberal segundo o qual todas as decisões legais devem ser formuladas e justificadas em uma linguagem universal (Fernando PERLATTO, 2011).

Sem diminuir a importância desse debate, mas, problematizando um outro aspecto, é importante que destaquemos que o que torna ainda mais difícil a reflexão sobre os enunciados do "Manual" é o fato de sua estrutura discursiva ser edificada por uma narrativa que mobiliza argumentos "científicos" e "biologizantes/naturalistas" na defesa dos seus posicionamentos, utilizando o argumento religioso apenas como “elemento complementar". Isso significa, por exemplo, que quando o "Manual" tece questionamentos sobre a Teoria de Gênero, ele se

13 De acordo com Perlatto, Rawls sustenta que os argumentos religiosos podem "ser mobilizados no debate público, desde que traduzidos para termos seculares quando justificados publicamente, não necessitando, por conseguinte, nenhum entendimento religioso prévio específico por parte dos participantes da discussão pública" (Fernando PERLATTO, 2013, p.142). 
ampara em argumentos ditos por biólogos ou por supostos "estudos científicos".

Podemos observar a estruturação discursiva supramencionada quando o "Manual" na parte dele chamada Reflexões Éticas responde às perguntas ("Por que ninguém pode decidir se transformar em homem ou mulher? ou Recusar a adoção aos homossexuais não representaria homofobia?") do seguinte modo: "Biologicamente, todo ser humano é menino ou menina. (...) É natural que o comportamento social (o gênero) esteja em harmonia com o sexo biológico. O contrário é sempre fonte de sofrimento" (CHAVES PARA A BIOÉTICA, 2013). A respeito da pergunta sobre a recusa à adoção aos homossexuais, diz o "Manual":

Ter um filho não é um direito! O filho não é um bem de consumo, que viria ao mundo em função das necessidades ou dos desejos dos pais. Embora o fato de alguém não poder ter filhos seja fonte de sofrimento, essa reivindicação dos lobbies homossexuais não é legítima. É preciso um homem e uma mulher para gerar um filho. Querer ignorar essa exigência biológica é um forte indício de que a reivindicação não é justa. E se houver algum direito a alegar, seria o 'direito da criança' a ter pai e mãe para poder construir sua personalidade: (CHAVES PARA A BIOÉTICA, p.73).

Sobre o fato de o "Manual" buscar fundamentar seus argumentos em estudos científicos, podemos observar que ele o faz de dois modos: no primeiro deles, tendo como exemplo ainda a parte da Teoria de Gênero, o "Manual" traz a "explicação cromossomática14" da Biologia para responder a pergunta: "o que nos faz ser menino ou menina?" (CHAVES PARA A BIOÉTICA, 2013, p.70). Explicação que, no limite, leva aos argumentos naturalistas e a explicações como a seguinte:

O que é homoparentalidade? Este termo designa o exercício da função de pais por dois adultos do mesmo sexo. (...) Essa reinvindicação oculta o direito de a criança conhecer o seu pai e a sua mãe e de crescer com eles. Se duas mulheres quiserem "ter filhos", a ciência

14 "O corpo de cada ser humano possui cerca de 70 bilhões de células. No núcleo de casa célula existem 23 pares de cromossomos, sendo um par XX para as meninas e um XY para os meninos" (CHAVES DA BIOÉTICA, 2013, p.70). 
Ihes permitirá contornar o problema da ausência do patrimônio genético masculino, apelando para um banco de esperma. Ora, quando a criança cresce questiona necessariamente a sua origem biológica. $\mathrm{E}$ para formar a sua personalidade, a criança precisa de diferenciação sexual. Além disso, essa situação peculiar cria uma desigualdade para as crianças privadas da sua filiação. (IBIDEM, p.72).

Ainda sobre o fato de se "fundamentar" em supostos "estudos científicos", vale mencionar que o "Manual" menciona posicionamentos de psicólogos, mesmo não citando fontes, e traz, na parte da Teoria de Gênero do "Manual”, no componente chamado Testemunho, a seguinte publicação:

Um estudo científico publicado no início do verão coloca em xeque a linha oficial que prevalecia até aqui, que acreditava a tese, segundo a qual não haveria nenhuma diferença em termos de saúde mental entre as crianças criadas por casais homossexuais e aquelas que 0 são por casais heterossexuais. Porque há uma divergência desses estudos de psicologia comportamental? A explicação está na qualidade do posicionamento de Regnerus [...] que teve o cuidado de efetuar sua pesquisa sobre um vasto grupo de adultos contrariamente ao que faziam os antigos estudos que se apoiavam em amostras ridiculamente fracas [...] Depois da análise do conjunto de respostas, a conclusão [...] é inevitável: o modelo familiar que repousa sobre "a união conjugal estável do pai e mãe biológica" [...] permanece "o ambiente mais apropriado para o desenvolvimento da criança. (CHAVES PARA A BIOÉTICA, 2013, p.74).

Por fim, importa-nos destacar que quando afirmamos que o "Manual" utiliza os argumentos religiosos como complementares aos supostos argumentos científicos e "biologizantes/naturalistas", estamos também fazendo alusão ao modo como o "Manual” é estruturado. Uma vez que, após os argumentos "científicos" supracitados, o "Manual” possui uma parte denominada $O$ que diz a Igreja e uma parte chamada Para Refletir, onde, por exemplo, nessa segunda parte após a exposição sobre a Teoria de Gênero, o "Manual” traz uma citação bíblica (Gênesis), um fragmento de uma carta de João Paulo II às mulheres e uma citação que diz: "E o Senhor Deus disse: 'Não é bom que o homem esteja só. Vou fazer uma auxiliar que lhe corresponda" (CHAVES PARA A BIOÉTICA, 2013, p.75). 


\section{CONSIDERAÇÕES FINAIS: QUESTIONAMENTOS PARA NÃO FINALIZAR}

A respeito da ação discursiva do "Manual" de mobilizar o discurso científico, ela possibilita que façamos as seguintes perguntas: essa complementariedade pode ser utilizada na deslegitimação de perspectivas contrárias às religiosas? Ou seria essa ação parte do processo de tradução sugerido acima por Habermas? Ou estamos apenas diante de um "mascaramento" do posicionamento religioso através de supostos argumentos científicos tomados como inequívocos e unívocos? Será uma estratégia colocar como necessária a complementariedade entre o discurso religioso e o discurso científico como uma forma de legitimação do religioso na escola pública laica? Ou ainda, será essa distinção entre a narrativa científica e religiosa apenas possível dentro de um quadro "formalista" como o habermasiano, não tendo sentido essa distinção, em termos de posicionamentos políticos, dentro dos aportes de outras perspectivas teóricas?

Na visão dos pesquisadores Medeiros e Monsores, que se amparam em Meyer e El-Hani e que criticam o uso da apropriação do discurso científico pelas estruturas religiosas, que só utilizam o científico seletivamente para afirmar seus posicionamentos, "o aparente debate pode dar ao religioso um fórum que é, de modo geral, desproporcional ao conhecimento que ele possui sobre o tema" (MEYER E EL-HANI, APUD, Cristiano MEDEIROS; Luciana MONSORES, 2014). Ademais, os pesquisadores consideram que o tipo de discurso utilizado é "incompatível com a pedagogia crítica e com as concepções de educação atuais, que veem a escola como um espaço de pluralidade cultural e interculturalidade" (2014). Para eles, a "escola é um espaço de respeito e valorização das diferenças e, nela, qualquer tipo de expressão sexual ou de gênero deve ser respeitada" (Cristiano MEDEIROS; Luciana MONSORES, 2014, p.11).

Se procurarmos pensar orientados pelo ponto de vista de Habermas, podemos questionar se as "falas" do "Manual" levam em conta a importância do pluralismo de ideias e operam com uma linguagem pública adequada para o funcionamento de um debate público democrático. Ou, se pelo contrário, o "Manual" opera com enunciados e narrativas que não reconhecem e/ou deslegitimam perspectivas contrárias às suas. 
Uma vez que uma estrutura discursiva, que ignora, deprecia ou deslegitima argumentos distintos aos seus, dificulta o diálogo democrático necessário, nega perspectivas de conhecimento.

Consideramos que o "Manual" possui uma estrutura discursiva que deve ser no mínimo questionada, quando, por exemplo, não leva em conta o monoparentalismo e o homoparentalismo e ao descredibilizar o argumento das chamadas Teorias de gênero e não os mencionar, como discursos legítimos, isto é, ao não levar em consideração os argumentos do "interlocutor", age em desacordo com as possibilidades de uma ação comunicativa democrática. Lembrando que o ato de discordar é diferente do ato de deslegitimar e de descredibilizar.

Por conseguinte, é muito importante destacar que se para Habermas no Estado constitucional os cidadãos não têm de se "contentar apenas com um modos vivendi, devendo e podendo expor seus argumentos e orientações, "é necessário que eles estejam, além disso, convictos da necessidade de viver em um ordem democrática" (HABERMAS, 2007, p.9). Isso significa que o reconhecimento dos argumentos religiosos só vale no limite do espaço normativo estabelecido por um poder governamental autônomo em relação aos decretos religiosos e que opere pelos princípios de igualdade e liberdade próprios à democracia constitucional, devendo ser rechaçados e denunciados, quando forem contrários aos direitos republicanos" (Philippe PORTIER, 2013, p.73). Significa também, de acordo com a nossa compreensão, que os argumentos não podem conter ou incitar violências e discriminações.

Portanto, torna-se imprescindível destacar que a aceitação dos argumentos religiosos, ou qualquer outro, mesmo na esfera da opinião pública, não se efetiva se os argumentos incentivarem, por exemplo, desigualdades, discriminações e violências de qualquer tipo. Seria esse o caso do "Manual" de Bioética?

Destarte, vale destacar que reconhecemos a legitimidade de diferentes discursos, incluindo o religioso, na esfera pública. Todavia, esses discursos devem ser articulados tendo como orientação os princípios democráticos, e devem fazer uso de uma linguagem apropriada para o diálogo democrático.

Por fim, consideramos que todo material, inclusive o Currículo Mínimo e qualquer outro manual, utilizado na disciplina de Ensino Religioso e sua execução de um modo apropriado devem levar em conta a 
pluralidade de perspectivas e religiões. E, ao se apresentar como instrumento de debate na esfera pública, possuir um discurso que respeite a pluralidade cultural, as expressões sexuais e de gênero e que permita seu diálogo com outros pontos de vista. Além disso, é imprescindível que haja uma qualificação adequada dos executantes (professores e demais agentes), sobretudo levando-se em consideração os mesmos princípios acima mencionados.

\section{REFERÊNCIAS}

ASAD, Talal. Formations of the Secular: Christianity, Islam, Modernity. Stanford University Press, 2003.

BIRMAN, Patrícia (org.). Religião e Espaço Público. São Paulo: Attar. 2003.

BUROCCHI, Áurea Marin; VITÓRIO, Jaldemir (Orgs). Religião e espaço público: cenários contemporâneos. São Paulo: Paulinas, 2015.

BUTLER, Judith. El género en disputa. El feminismo y la subversión de la identidad. Barcelona: Paidós, 2007.

CAPUTO, Stela Guedes. Educação em Terreiros e como a Escola se relaciona com as Crianças de Candomblé. Editora Pallas. Rio de Janeiro. 2012.

CASANOVA, José. Religiones Publicas en el mundo moderno. Madrid: Editorial PCP, 1994. CHAVES PARA A BIOÉTICA (Keys to bioethics). Brasília-DF, 2013. (Manual de Bioética). RIO DE JANEIRO. CURRÍCULO MÍNIMO DE ENSINO RELIGIOSO. Secretaria de Estado de Educação do Rio de Janeiro, 2013.

EAGLETON, Terry. O debate sobre Deus: razão, fé e revolução. RJ: Nova Fronteira, 2011. FONSECA, Claudia. Homoparentalidade: novas luzes sobre o parentesco. Revista de Estudos Feministas, Florianópolis, v.16 n.3, p.769-783, 2008.

FOUCAULT, Michel. A ordem do discurso. Brasil: Loyola, 2005.

FRASER, Nancy. Rethinking the public sphere: a contribution to the critique of the actually existing democracy. In: CALHOUN, C. Habermas and the public sphere. Londo. MIT Press, 1992.

O que é crítico na teoria crítica? Habermas e gênero. Ex Aequo: reconceptualizações filosóficas e de teoria política (perspectivas feministas), n. 8, 2003.

GIUMBELLI, Emerson. A presença do religioso no espaço público: modalidades no Brasil. Religião e Sociedade, v.28, n.2, Rio de Janeiro, p. 80-101, 2008.

Ensino Religioso em Sala de Aula: Observações a partir de Escolas Fluminenses. Antropolítica, v. 23, p. 35-55.

A religião nos limites da simples educação: notas sobre livros didáticos 
e orientações curriculares de ensino religioso. Revista de Antropologia. USP: São Paulo, n.3, v.1, 2010.

HABERMAS, Jürgen. Entre naturalismo e religião: estudos filosóficos. Trad. Flávio B. Siebeneichler. Rio de Janeiro: Tempo Brasileiro, 2007.

O discurso filosófico da modernidade. São Paulo: Martins Fontes, 2002.

Mudança estrutural da esfera pública: investigações quanto a uma categoria da sociedade burguesa. Rio de Janeiro:Tempo Brasileiro, 1984.

Fé e Saber. São Paulo: Editora Unesp, 2013.

Agir comunicativo e razão descentralizada. Rio de Janeiro: Tempo Brasileiro, 2002.

Further Reflections on the Public Sphere. In: CALHOUN, C. Habermas and the Public Sphere. London: MIT Press, 1992.

Direito e democracia: entre facticidade e validade. Rio de Janeiro: Ed. Tempo Brasileiro, vol. II, 1997.

HERNÁNDEZ, Jimena de Garay; UZIEL, Anna Paula. Famílias homoparentais e escola: entre a vigilância e a transformação. Momento, v. 23, n. 2, p. 9-24, jul./dez. 2014

HORÁCIO, Heiberle Hirsgberg. Religiosidades diversas e "ensino religioso de caráter confessional e plural”: análise de uma experiência na educação pública do Estado do Rio de Janeiro. Anais da Terceira Jornada de Ciências Sociais da UFJF, 2014. ISSN: 2358-5285.

Apontamentos sobre o Ensino Religioso no Estado do Rio de Janeiro após a elaboração do currículo mínimo. Anais do XIV Simpósio Nacional da ABHR, UFJF, 2015. JUNQUEIRA, Sérgio Rogério Azevedo. Ciência da Religião aplicada ao ensino religioso. In: USARSKI, Frank; PASSOS, João Décio. Compêndio de Ciência da Religião. São Paulo: Paulinas: Paulos, 2013.

LATOUR, Bruno. Jamais fomos modernos: ensaio de antropologia simétrica. RJ: Ed. 34, 1994 .

LOURO, Guacira Lopes. Gênero, sexualidade e educação: uma perspectiva pós- estruturalista. Petrópolis: Vozes, 1997.

MACINTYRE, Alasdair. Depois da Virtude. Bauru, São Paulo: EDUSC, 2001.

MATOS, Marlise. Teorias de gênero ou teorias e gênero? Se e como os estudos de gênero e feministas se transformaram em um campo novo para as ciências. Revista de Estudos Feministas. vol.16 no.2 Florianópolis May/Aug. 2008

MEDEIROS, Cristiano Sant'Anna de; MONSORES, Luciana Helena Os 10 anos do Ensino Religioso no Estado do Rio de Janeiro e as diferenças de gênero. Anais do III Seminário Nacional de Educação, Diversidade Sexual e Direitos Humanos; Vitória, 2014.

MELLO, Rodrigo Chaves de. Do social em movimento aos movimentos sociais ou por uma leitura antijurídica de democracia. 2014, p. 150. Tese de doutorado, Programa de 
Ciências Sociais, UFJF, Juiz de Fora, MG.

MONTERO, Paula Religião, pluralismo e esfera pública no Brasil. Novos Estudos CEBRAP, 74: 47-65, 2006.

Controvérsias religiosas e esfera pública: repensando as religiões

como discurso. Religião e Sociedade: RJ, vol32. $n^{\circ} 1,2012$.

MOUFFE, Chantau. El retorno de lo político. Ediciones Paidós Ibérica S.A., 1999.

ORO, Ari Pedro; STEIL, Carlos Alberto; CIPRIANI, Roberto; GIUMBELLI, Emerson (Org.) A religião no espaço público: atores e objetos. São Paulo: Terceiro Nome, 2012.

PASSOS, João Décio. Ensino Religioso: mediações epistemológicas e finalidades pedagógicas. In: SENA, Luzia. Ensino religioso e formação docente: ciência da religião e ensino religioso em diálogo. São Paulo: Paulina, 2007.

PERLATTO, Fernando. Política, religião e democracia no Brasil: um diálogo com Habermas, Taylor e Eagleton. Numen: revista de estudo e pesquisa da religião. Juiz de Fora: Ed. UFJF, v.16, n.1, 2013.

Habermas, a esfera pública e o Brasil. Revista Estudos Políticos.

Número 4, 2012/01.

PORTIER, Philippe. Democracia e religião no pensamento de Jürgen Habermas. Numen: revista de estudo e pesquisa da religião. Juiz de Fora: Ed. UFJF, v.16, n.1, 2013.

RANQUETAT, Carlos Eduardo. Religião em Sala de Aula: O Ensino Religioso nas Escolas Públicas Brasileiras. CSOnline - Revista Eletrônica de Ciências Sociais, v. 01, p. 163-180, 2007.

RAWLS, John. Liberalismo político. São Paulo: Ática, 2000.

RODRIGUES, Elisa. Ensino Religioso, tolerância e cidadania na escola pública. Numen: revista de estudo e pesquisa da religião. Juiz de Fora: Ed. UFJF, v.16, n.1, 2013.

SENA, Luzia (Org.). Ensino religioso e formação docente: ciência da religião e ensino religioso em diálogo. São Paulo: Paulina, 2007.

SILVA, Boris Maia e. Ensino religioso e resistência moral: dilemas na implantação da lei 3459/00 no Rio de Janeiro. In: Revista Ética e Filosofia Política, n¹5, volume 1, maio 2012. SILVEIRA, Emerson Sena da. (Org.) Religião, política e espaço público no Brasil. Discussões teóricas e investigações empíricas. São Paulo: Fonte Editorial, 2015.

TAYLOR, Charles. A Secular Age. Cambridge: Harvard University Press, 2007.

TEIXEIRA, Faustino. O “ensino do religioso" e as Ciências da Religião. Belo Horizonte: Horizonte, v,9, n.23, out/dez, 2011.

USARSKI. Frank (org.). O espectro disciplinar da Ciência da Religião. São Paulo: Paulinas, 2007.

Submetido em: 10-8-2016

Aceito em: 16-12-2016

Mandrágora, v.22. n. 2, 2016, p. 125-147 